\title{
Availability of Tracer Drugs and Implementation of Their Logistic Management Information System in Public Health Facilities of Dessie, North-East Ethiopia
}

This article was published in the following Dove Press journal:

Integrated Pharmacy Research and Practice

\section{Mulate Belete Demessie Birhanu Demeke Workneh' Solomon Ahmed Mohammed (D) ' \\ Abel Demerew Hailu (D) ${ }^{2}$ \\ 'Department of Pharmacy, College of Medicine and Health Science, Wollo University, Dessie, Ethiopia; ${ }^{2}$ Department of Pharmacy, Dessie Health Science College, Dessie, Ethiopia}

Background: Tracer drugs are the representative of essential medicines and satisfy the priority healthcare needs of the population. Managing tracer drugs through logistics management information systems is a strategy to enhance their smooth flow for continuous provision of quality health service. This study assessed the availability of tracer drugs and implementation of their logistic management information system in public health facilities of Dessie, North-East Ethiopia.

Methods: Cross-sectional study was conducted from September 15-30, 2017, in all public health facilities of Dessie. The data were collected by reviewing tracer drugs logistic formats and conducting physical inventory. Key informant interview was employed to all pharmacy heads and store managers. Data analysis was done using statistical package for social science version 20 and Microsoft Excel 2010.

Results: Twelve tracer drugs were managed by health facilities. The overall mean availability, mean duration, and average frequency of stock out of tracer drugs (last 6 months) were $74.7 \%, 48.8$ days, and 1.43 , respectively. In eight health facilities, logistic records were available, but all health facilities did not use stock cards. Also, 3 out of 9 used the health commodity management information system. On average, $77.8 \%$ of the tracer drugs had bin cards, of which, $86 \%$ were updated. The discrepancy between physical count and stock keeping records was ranged from $0 \%$ to $100 \%$. The causes of stock out were inadequate supply, lack of recording forms, and their inconsistent use.

Conclusion and Recommendations: The availability of tracer drugs was less than the recommended percent, and inadequate supply, poor availability and use of recording forms were the reasons for stock out. Thus, health facility managers and pharmacy heads should work in harmony to ensure uninterrupted supply and implement a logistic management information system.

Keywords: logistic management information system, overstock, public health facility, stockouts, tracer drugs

\section{Introduction}

The concept of tracer drugs (TDs) as essential medicines (EMs) was pioneered by the World Health Organization (WHO) in 1977. At inception, EMs was defined as medicines that are of utmost importance, and are basic, indispensable, and necessary for the health needs of the population. ${ }^{1}$ They are selected with due regard to public health relevance, evidence of efficacy, and safety as well as cost-effectiveness. ${ }^{2}$

\section{Mohammed}

Department of Pharmacy, College of

Medicine and Health Science, Wollo

University, P.O. Box: II45, Dessie,

Ethiopia

Tel +25 I 910504378

Email ahmedsolomon2I@gmail.com 
Ethiopian-integrated pharmaceutical logistics system was aimed to integrate all vertical programs into one supply chain and deliver pharmaceuticals directly to health facilities every other month from pharmaceutical supply agency. ${ }^{3}$ It used pharmaceutical logistics management information system (LMIS) as a system of records and reports of pharmaceuticals data to ensure the continuous availability of all pharmaceuticals that are required for patient care. At the same time, responding to sudden increases in drug demand and ensuring that adequate supplies should always be in place to deal with any emergencies that arise. ${ }^{4,5}$

An effective LMIS collects essential data about stock status and consumption so that it ensures accountability and cost-effectiveness for all products in the supply chain. ${ }^{4}$ Lack of effective LMIS not only affects the availability of EMs but also significantly affects the efficiency of the healthcare system. Public health supply chain managers in developing countries do not have regular access to reliable and real-time information for procurement as well as supply management decision-making. Typically, these managers rely on past experiences; guesswork, and poor quality information to make supply chain decisions. ${ }^{5-7}$

Even though medicines are the most significant tool that society possesses to prevent, alleviate, and cure diseases, more than one-third of the world's population lacks reliable access to EMs, a situation that undermines health systems' objectives of equity, efficiency, and health development. ${ }^{8,9}$ Lack of medicines in the public sector forces patients to go without or purchase medicines from private outlets where generic medicines cost on average six times more than their international reference price while originator brands are generally even more expensive. ${ }^{10-12}$

More than that shortages of EMs and spending on unnecessary or low-quality medicines also have a high cost wasted resources and even death at the worst end. Although significant efforts have been made to improve access to EMs in the last decade, many people are still suffering from preventable or treatable diseases in the region. ${ }^{13,14}$ In addition to their impact on the quality of patient care, ruptures of EMs stocks may contribute to an increased workload for already stressed health-care staff as patients require additional visits or referrals to access recommended services. These additional visits and/or referrals may contribute to low morale and high turnover among staff at rural health centers, further affecting service quality and hindering the scalability of health programs. ${ }^{6}$
A survey conducted in 24 health centers of Addis Ababa reported that the majority of $18(75.0 \%)$ of the health centers often stocked out some non-program TDs while $9(37.5 \%)$ of the health centers often overstocked some non-program TDs. ${ }^{15}$ Similar research done in Gondar town showed that the overall average availability of tracer EMs was 23.67 (91\%) and stoked out for an average of $2.33(9 \%)$ and $5.83(22.4 \%)$ TDs over the six months during the survey period. ${ }^{16}$

A study in Uganda pointed out that several factors influenced the availability of EMs. Some of these were identified as; drug requisitions based on neither morbidity nor consumption methods of quantification, requisitions based on credit availability, poor distribution of logistics, delays during distribution, supplying medicines with short shelf life, low usage drugs, and pushing some medicines. ${ }^{17}$ Factors such as lack of consistency in the schedules of supply delivery, lack of consideration of the unique peculiarities that exist at the different health facilities, lack of strong governance and coordination of the national system in Ethiopia were also quoted to be adversely affecting the availability of EMs and supplies, among others. ${ }^{16}$

Determining TDs availability and an in-depth understanding of logistic management information system implementation will empower public health governors and decision-makers' effort to improve access, develop human resources required to manage TDs and improve supply chain. Therefore, this study measured the availability of TDs and the implementation of their logistic management information system in public health facilities of Dessie, North-East Ethiopia.

\section{Methods}

\section{Study Area and Period}

The study was conducted in public health facilities of Dessie from September 15-30/2017. According to the 2014 national census conducted by the Central Statistical Agency of Ethiopia, Dessie has a total population of $151,174 .{ }^{18}$ It is the capital city of South Wollo which is one of the 11 zones of Amhara Regional State. The zone is found in the North-east part of Ethiopia. Dessie is $401 \mathrm{~km}$ away from Addis Ababa, the capital city of Ethiopia. In the town, there were two public hospitals, seven public health centers, and forty-three private drug vendors at the time of the study. The health institutions have been offering basic health services to meet the health needs of the population through different units. 


\section{Study Design}

A cross-sectional study that entailed retrospective and observational data collection approach was conducted by reviewing TDs bin cards, Report and Requisition Form (RRF), and conducting the physical count. The availability of TDs was assessed using different approaches (reviewing stock records, and conducting physical count) and stock out of TDs, frequency, and duration of stock-outs of TDs for six months, and at the day of visit were assessed retrospectively. Key informants interview was also employed to explore the availability of TDs and implementation of their logistic management information system.

\section{Study Units and Participants}

Twelve TDs were adapted from the list of TDs reported in health management information system of the Federal Ministry of Health. ${ }^{19}$ These TDs were expected to be availed in all public health facilities. Essential data were retrieved by reviewing bin cards and RRF used for managing the TDs in all health facilities (two public hospitals and seven public health centers). All pharmacy heads (9) and store managers (9) in the health facilities were included in the study for the key informant interview as they were in charge of the overall activities of pharmaceutical logistics and hence able to provide the needed information.

\section{Inclusion and Exclusion Criteria}

All public health facilities which manage TDs in the town and all TDs in health management information system of federal ministry of health were included. Pharmaceuticals that were specific to health facility and were not listed in health management information system of Federal Ministry of Health were excluded.

\section{Variables}

The outcome variable of this study was availability of TDs. Funding, procurement, distribution, patient load, management support, availability logistic records, and availability of motivated and trained manpower were predictor variables.

\section{Data Collection}

Records of TDs were abstracted by reviewing TDs logistics records using structured checklists. The quantitative data were collected by one experienced druggist in the supply chain after recruiting and half-day training, but had no working relationship with the institutions in the study. The principal investigators coordinated and observe the quantitative data collection.

For the qualitative part of the study, the semi-structured interview guide consisted of background information of key informants and probing questions were prepared. The principal investigator conducted the in-depth interview which lasted an average of 15 minutes. All interviews were audio-recorded and transcribed verbatim. Key informants were selected by the town logistics officer. Purposive sampling was used to select all pharmacy heads and store managers in selected health facilities for the qualitative part of the study.

\section{Data Collection Instruments}

A structured checklist adopted from Logistics Indicator Assessment Tool (LIAT) was used to collect the logistics data. $^{20}$

\section{Data Quality Assurance}

The structured checklist was properly designed and pretested on one hospital and one health center as the sample units had different volumes, one health facility was selected from each to see the soundness of the questionnaire and to make necessary corrections before starting the study. Some aspects of the tool which were of less significance to objectives of the study (organizing, staffing, financing, etc.) were excluded from the tool following the piloting schemes. All completed questionnaire was examined for completeness and consistency during data collection, analysis, and interpretation.

\section{Data Analysis and Presentation}

The data were entered and analyzed using statistical package for social science (SPSS) version 20 and Microsoft Excel 2010 and the results were presented in the form of tables and graphs.

\section{Results}

Among the 7 health centers, 5 were low volume and 2 were high volume, while both hospitals were high volume. The minimum distance was 1 kilometer and the maximum was 12 kilometers away from the Woreda health office with mean and standard deviation of $6.2 \pm 4.02$. On the other hand, health facilities were located 1 and 15 kilometers away from Pharmaceutical Supply Agency (PSA) 
at a minimum and maximum, respectively, with mean and standard deviation of $10.1 \pm 5.06$.

Twelve tracer drugs were managed by health facilities. Eight $(88.9 \%)$ health facilities encountered stock out for some TDs whereas the other two TDs 2(22.2\%) health facilities faced overstocked for Amoxicillin $250 \mathrm{mg}$ tablet and Paracetamol 500mg. Eight TDs were stocked out in 4 health facilities on the date of data collection; of these, five were reported to be often stocked out in two or more health facilities. The mean availability of TDs was 8.22 (74.7\%) (Table 1).

To estimate days out of stock in the past six months, only six health facilities had stock records. The most commonly out of stocked TDs was Ferrous Sulphate (FeSo4) 150mg + Folic acid $0.5 \mathrm{mg}$ and was encountered in seven out of nine health facilities $(77.7 \%)$ whereas stock out of oral rehydration salt, Diphtheria Pertussis Tetanus Human Influenza B (DPT-Hib) vaccine and Medroxyprogesterone $150 \mathrm{mg} / \mathrm{mL}$ injection were encountered only in one out of nine health facilities (Figure 1).

Three $(50 \%)$ of the health facilities encountered stock out Artemether $20 \mathrm{mg}$ and lumefantrine $120 \mathrm{mg}$ and was not available for 105 days. The highest (205) mean frequency of stock out in the last six months was recorded for TTC eye ointment $1 \%$ (Table 2 ).

The highest frequency of stock out $(7$ times) was recorded for Ferrous Sulphate $150 \mathrm{mg}+$ Folic acid $0.5 \mathrm{mg}$ while Oral rehydration salt, Medroxyprogesterone150mg/ $\mathrm{mL}$ injection, and DPT-Hep-Hib vaccine were stock out once (Table 3).

Stock cards, Internal Facility Report, and Resupply Form (IFRR) and RRF were available in eight HFs to manage TDs but all health facilities did not use stock

Table I Availability TDs in Public Health Facilities, Dessie, Ethiopia, 2017

\begin{tabular}{|l|l|l|l|}
\hline S.No. & Health Facility Code & Frequency & Percentage \\
\hline 1 & 01 & 10 & 90.9 \\
2 & 02 & 11 & 100 \\
3 & 03 & 10 & 90.9 \\
4 & 04 & 10 & 90.9 \\
5 & 05 & 10 & 90.9 \\
6 & 06 & 5 & 45.4 \\
7 & 07 & 7 & 63.6 \\
8 & 08 & 8 & 72.7 \\
9 & 09 & 3 & 27.3 \\
\hline \multicolumn{2}{|l|}{ Mean availability } & 8.22 & 74.7 \\
\hline
\end{tabular}

cards. In addition to manual recording, three out of nine health facilities used health commodity management information system (HCMIS) software to manage TDs. In terms of utilization, all health facilities except one health center used RRF to order TDs from health facilities pharmaceutical stores to PSA and IFRR to request TDs from health facilities pharmaceutical stores. Similarly, receiving and issuing of TDs were also made using receiving voucher/model 19 and issuing voucher/model 22, respectively.

Availability, updating status of bin cards, and accuracy of keeping logistics records were assessed for the TDs. Bin cards were available for the majority of TDs. On average, $77.8 \%$ of the TDs had bin cards of which $86 \%$ were updated (Table 4).

As to the accuracy of keeping stock records, the maximum discrepancy of amoxicillin $125 \mathrm{mg} / 5 \mathrm{~mL}$ and Amoxicillin $250 \mathrm{mg}$ were $100 \%$ while the minimum was 9.1\% (Table 5).

Only six health facilities report stock on hand quantities to the PSA of Ethiopia every other month but $66.7 \%$ of health facilities reported TDs loss and adjustment data in the reporting period. Five of the health facilities sent the report in the last month from the day of the survey and one health facility sent the report in a similar month of the survey (Figure 2). Besides, three health facilities used HCMIS software to manage TDs in the store and all were functional at the time of the survey. The health facilities thus used the HCMIS mainly to trace the expiry date of drugs and for determining order quantity (Figure 3).

Unfilled and incomplete logistic record forms were the main reason for stock out for TDs among others. In the three health facilities, there was no logistic data. Even though some health facilities had logistic data, there was an inappropriate filling which in turn leads to the fact that the health facilities did not request the right amount of TDs at the right time from PFSA and facility store. Some participants stated that PFSA could not able to supply TDs, such as Ferrous Sulfate with Folic Acid and Tetracycline eye ointment, even if they requested timely. The other reason was the absence of stock card filling, which should be filled and regulated by the pharmacy head of health facilities to minimize the discrepancy of stock record keeping. The overburden of work made the store manager be extremely exhausted and overwhelmed and absences of indemnity for staff exacerbated the problem.

Transportation problem was also mentioned as a reason for stock-outs of TDs. The study documented that seven of 


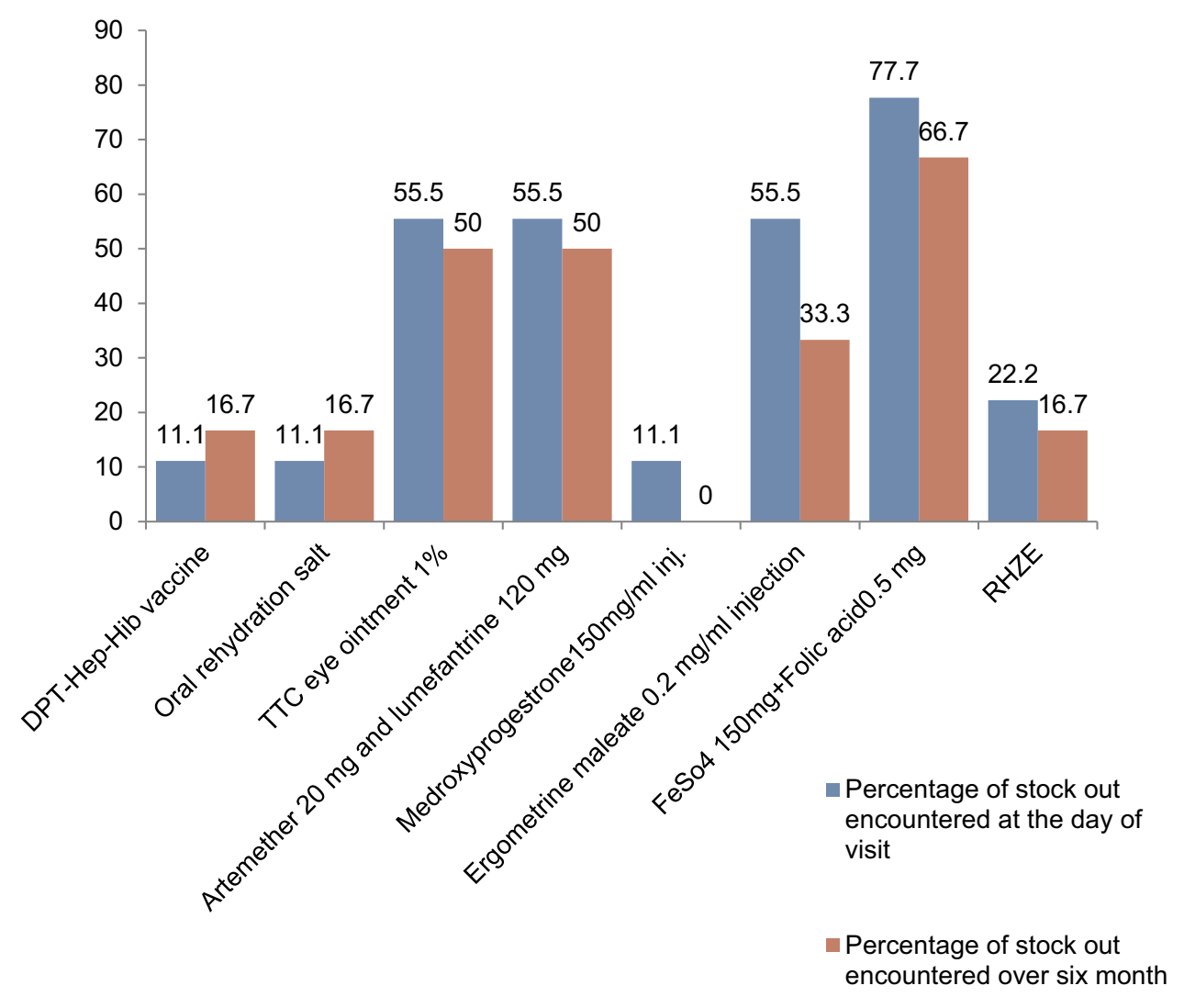

Figure I Percentage of TDs that were stock out in HFs, Dessie, Ethiopia, 2017.

nine health facilities did not have their vehicle to transport TDs and then PFSA had not been delivering the drugs at a needed time to the health facilities. Regarding lead time, it took two weeks to one month for the majority of the health facilities to receive TDs from PFSA after an order had been initiated. Lack of sustainable supervision from Woreda Health Office, Zone Health Department, and PFSA regarding on availability of TDs and their implementation of LMIS worsen the situation.

\section{Discussion}

This study found that eight (88.9\%) health facilities faced stock out for some TDs. A similar study conducted in Addis Ababa public health centers reported $75 \%$ of stock out ${ }^{15}$ and in Sofala Mozambique, a total of $96 \%$ of clinics were missing at least one TDs. ${ }^{21}$ This might be attributed to poor LMIS as three out of nine health facilities used HCMIS, $14 \%$ of the TDs bin cards were not updated and none of health facilities were not used stock cards. Key

Table 2 TDs Stock Out in the Last Six Months in Public Health Facilities, Dessie, Ethiopia, 2017

\begin{tabular}{|c|c|c|c|c|}
\hline $\begin{array}{l}\text { S. } \\
\text { No. }\end{array}$ & Tracer Drugs & $\begin{array}{l}\text { Stock Out Encountered, } \\
\text { n (\%) }\end{array}$ & $\begin{array}{l}\text { Mean Frequency of Stock } \\
\text { Out }\end{array}$ & $\begin{array}{l}\text { Mean Stock Out } \\
\text { Day }\end{array}$ \\
\hline I & $\begin{array}{l}\text { Artemether } 20 \mathrm{mg} \text { and lumefantrine } \\
120 \mathrm{mg}\end{array}$ & $3(50)$ & 1 & 105 \\
\hline 2 & RHZE & $\mathrm{I}(16.7)$ & 1 & 15 \\
\hline 3 & Ergometrine maleate $0.2 \mathrm{mg} / \mathrm{mL}$ injection & $2(33.3)$ & 1.5 & 43 \\
\hline 4 & FeSo4 I50mg+Folic acid0.5 mg & $4(66.7)$ & 1.5 & 78 \\
\hline 5 & DPT-Hep-Hib vaccine & $\mathrm{I}(\mathrm{I} 6.7)$ & 1 & 35 \\
\hline 6 & Oral rehydration salt & $\mathrm{I}(16.7)$ & 2 & 24 \\
\hline 7 & TTC eye ointment $1 \%$ & $3(50)$ & 2.5 & 42 \\
\hline \multicolumn{2}{|c|}{ Average } & $2.14(35.73)$ & $\mathrm{I} .43$ & 48.86 \\
\hline
\end{tabular}


Table 3 TDs Stock Out at the Day of Visit in Public Health Facilities, Dessie, Ethiopia, 2017

\begin{tabular}{|l|l|l|l|}
\hline $\begin{array}{l}\text { S. } \\
\text { No. }\end{array}$ & Tracer Drugs & $\begin{array}{l}\text { Number of Stock Out in Health } \\
\text { Facilities }\end{array}$ & $\begin{array}{l}\text { Percentage of Stock Out in Health } \\
\text { Facilities }\end{array}$ \\
\hline 1 & $\begin{array}{l}\text { Artemether } 20 \mathrm{mg} \text { and lumefantrine } \\
\text { I20mg }\end{array}$ & 5 & 55.5 \\
2 & TTC eye ointment $1 \%$ & 55.5 \\
3 & Ergometrine male ate $0.2 \mathrm{mg} / \mathrm{mL}$ & 5 & 55.5 \\
4 & injection & 7 & 77.7 \\
5 & FeSo4 I50mg+Folic acid0.5 mg & 1 & 11.1 \\
6 & Oral rehydration salt & 2 & 22.2 \\
7 & RHZE & 1 & 11.1 \\
8 & Medroxyprogesterone I $50 \mathrm{mg} / \mathrm{mL}$ inj. & 1 & 11.1 \\
\hline
\end{tabular}

Table 4 Bin Card Availability and Update for TDs in Public Health Facilities, Dessie, Ethiopia, 2017

\begin{tabular}{|c|c|c|c|c|}
\hline $\begin{array}{l}\text { S. } \\
\text { No. }\end{array}$ & TDs & $\begin{array}{l}\text { Numbers of HFs That Had } \\
\text { Bin Card }\end{array}$ & $\begin{array}{l}\text { Percentage of HFs That Had } \\
\text { Bin Card }\end{array}$ & $\begin{array}{l}\text { Bin Card Updated, } \\
\text { n (\%) }\end{array}$ \\
\hline I & Amoxicillin $125 \mathrm{mg} / 5 \mathrm{~mL}$ & 5 & 83.3 & $3(60)$ \\
\hline 2 & Amoxicillin $250 \mathrm{mg}$ & 5 & 83.3 & $5(100)$ \\
\hline 3 & Oral rehydration salt & 3 & 50 & $2(66.7)$ \\
\hline 4 & $\begin{array}{l}\text { Artemether } 20 \mathrm{mg} \text { and lumefantrine } \\
120 \mathrm{mg}\end{array}$ & 4 & 66.7 & $4(100)$ \\
\hline 5 & Mebendazole $100 \mathrm{mg}$ & 5 & 83.3 & $5(100)$ \\
\hline 6 & TTC eye ointment $1 \%$ & 4 & 66.7 & $3(75)$ \\
\hline 7 & Paracetamol $500 \mathrm{mg}$ & 6 & 100 & $5(83.3)$ \\
\hline 8 & RHZE(I50mg/75mg/400mg/275mg) & 6 & 100 & $6(100)$ \\
\hline 9 & $\begin{array}{l}\text { Medroxyprogesterone } 150 \mathrm{mg} / \mathrm{mL} \\
\text { inj. }\end{array}$ & 5 & 83.3 & $5(100)$ \\
\hline 10 & $\begin{array}{l}\text { Ergometrine maleate } 0.2 \mathrm{mg} / \mathrm{mL} \\
\text { injection }\end{array}$ & 4 & 66.7 & $2(50)$ \\
\hline II & FeSo4 I50mg+Folic acid $0.5 \mathrm{mg}$ & 5 & 66.7 & $4(100)$ \\
\hline 12 & DPT-Hep-Hib vaccine & 5 & 83.3 & $5(100)$ \\
\hline \multicolumn{2}{|c|}{ Average availability in \% } & & 77.8 & 77.8 \\
\hline
\end{tabular}

Table 5 Percentage of Discrepancy of TDs in Public Health Facilities, Dessie, Ethiopia, 2017

\begin{tabular}{|l|l|l|l|}
\hline $\begin{array}{l}\text { S. } \\
\text { no }\end{array}$ & $\begin{array}{l}\text { TDs Having } \\
\text { Discrepancy from } \\
\text { Bin Card }\end{array}$ & $\begin{array}{l}\text { Minimum } \\
\text { Discrepancy } \\
\text { in \% }\end{array}$ & $\begin{array}{l}\text { Maximum } \\
\text { Discrepancy } \\
\text { in \% }\end{array}$ \\
\hline I & Amoxicillin I25 mg/5mL & 9.1 & 100 \\
2 & Amoxicillin $250 \mathrm{mg}$ & 10 & 100 \\
3 & Oral rehydration salt & 26 & 80 \\
4 & Mebendazole I00 mg & 46.74 & 74 \\
5 & DPT-Hep-Hib vaccine & NA & 33 \\
\hline
\end{tabular}

Abbreviation: NA, not applicable. informant interview also revealed that the absence and incomplete logistic data were the main reason for stock out for TDs. On the other hand, the present study revealed that two TDs that were reported to be often overstocked in two health centers. This might be due to the tendency of health facilities to procure TDs in large quantities without standard procurement method believing that the drug might not be available at PFSA for the next order.

On average, $74.7 \%$ of the TDs were available on the day of the visit. This result indicated that each health facility was stoked out for an average of 2.81 (25.3\%) 


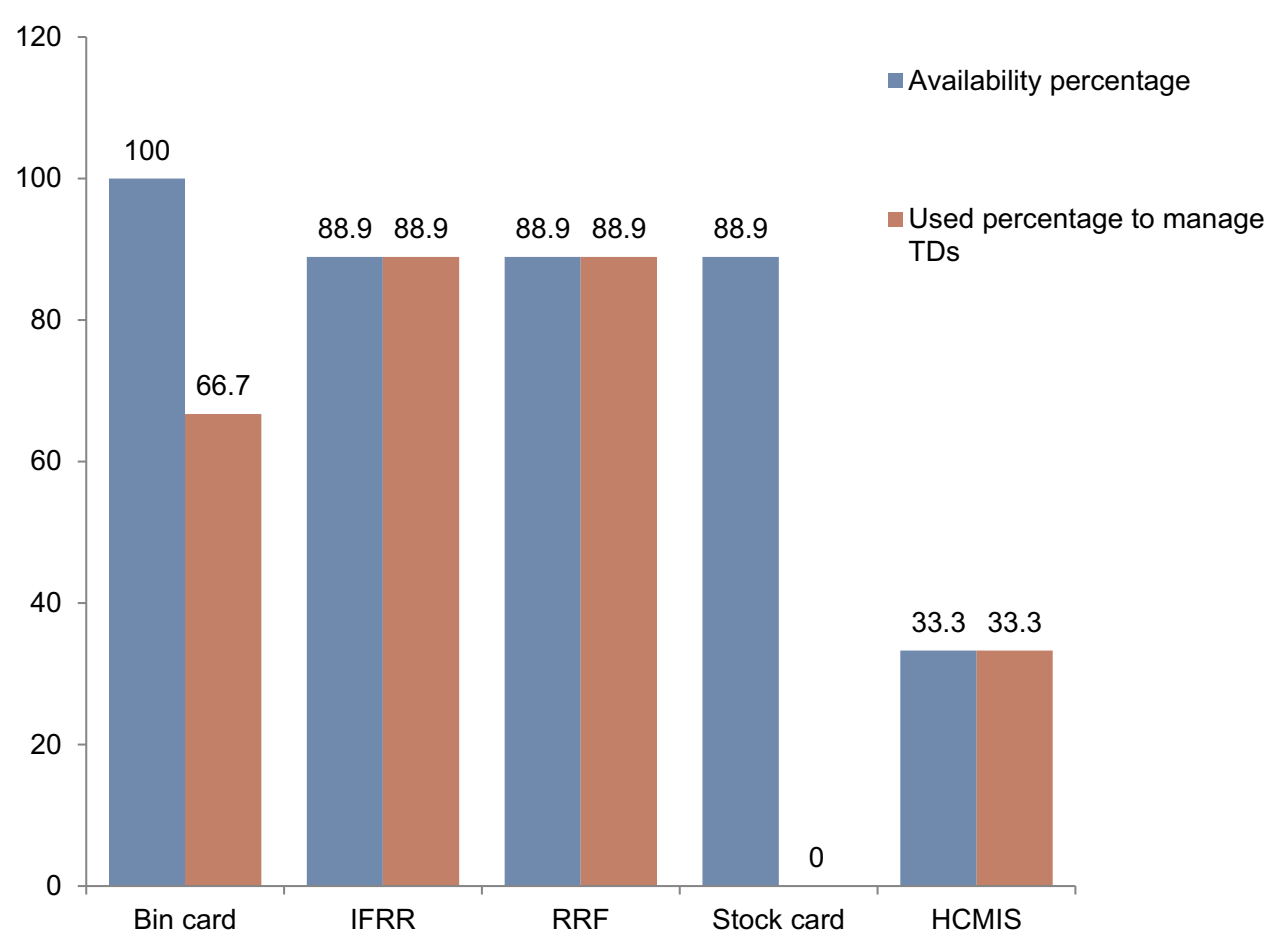

Figure 2 Types and availability of logistics forms in HFs, Dessie, Ethiopia, 2017 ( $n=9)$.

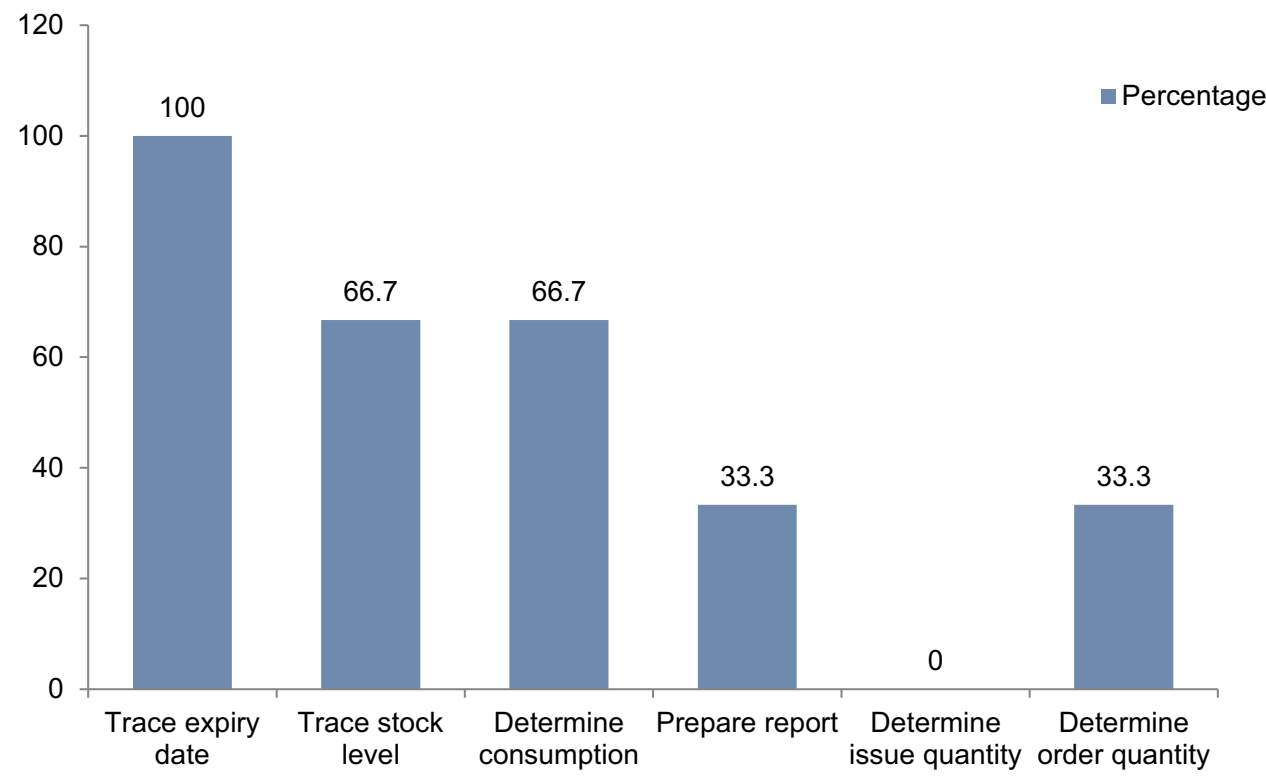

Figure 3 Use of health commodity management information system by the HFs, Dessie, Ethiopia, $2017(n=3)$.

during the survey period. The availability of TDs documented in the present study was better than the situation in Sub-saharan countries, such as Uganda $(45.7 \%),{ }^{22}$ Ghana Bulisa district $(64.1 \%),{ }^{23}$ Kenya $(20 \%),{ }^{24}$ and Jimma, South Western Ethiopia (55.6\%), ${ }^{25}$ but lower than Ghana $(85 \%),{ }^{22}$ Uganda Kaliro district $(79.53 \%)^{17}$ and Addis Ababa (85.4\%). ${ }^{15}$
The frequency and duration of stock-outs of the TDs were assessed in only six health facilities since the rest three did not have logistic data. Among the TDs, stock out for Feso4 with Folic acid, Tetracycline eye ointment 1\%, Artemether $20 \mathrm{mg}$, and Lumefantrine 120mg and Ergometrine injection were encountered in the majority of the health facilities. The reasons for Feso4 with Folic acid stock out were due to 
unavailability in PFSA. Similarly, in Ghana unavailability of stock from the central warehouse was the reason for stock out of TDs. ${ }^{22}$ In some health facilities, trend drug use contributed to stock out Ergometrine as it was largely substituted by Oxytocin. On the other hand, Tetracycline eye ointment 1\% stock out was attributed to failure to initiate an order by health facilities, while Artemether +Lumefantrine was stock out for a longer time as a result of a reduction in the prevalence of malaria. The stock-out duration for Arthemeter +Lumefanterine was around 3.5 months which was consistent with research done in Addis Ababa in which the stock out duration was 3 months. ${ }^{15}$ The stock-out duration was also comparable (4 months) in Tanzania ${ }^{26}$ and (72.9 days) in Tanzania and Uganda. ${ }^{17}$

This study articulated that not all TDs in the store had bin cards. Among TDs which had bin cards, one-fourth was not updated. Since bin cards provide essential data items on stock status, expiry date, and loss adjustment, lack of updated bin cards contributed to a lack of adequate stock control systems, which in turn contributed to stock out of TDs thereby resulting in interrupted and poor pharmaceutical services to patients.

A similar study conducted in Bangladesh, Swaziland, and West Africa region, Mali and Lesotho, in 2012, revealed that untimely and often inaccurate data, low submission rates, and a lack of standardized, and user-friendly data collections tools resulted in poorly functioning supply chain management. ${ }^{5}$

The current study revealed that store managers did not fill bin card and stock card which consequently compromised the quality of RRF to be sent to PFSA. This might be due to the absence and inappropriate use of logistics data by store managers. This resulted in a shortage and accumulation of TDs in health facilities and/or PFSA store. This showed that the pharmaceutical logistics system has not been improved. So, the availability was far from the WHO recommended target of $100 \%{ }^{27}$ Unavailability of TDs put patients on less effective and less safe substitutes. Moreover, forced patients to revert to the private sector where increasing the chance of incurring catastrophic health expenditures. $^{28}$

This study found that six out of the nine health facilities did not have computerized LMIS in the store. This might be due to a lack of awareness about how HCMIS simplifies works. Though HCMIS was used by one-third of the health facilities, the majority of the participants witnessed the relevance of the logistics system in facilitating the drug supply management. When used effectively, automation eases the tedious work, saves personnel time, and promotes the quality of pharmaceutical services. ${ }^{29}$

The present study showed a 100\% discrepancy between recorded balance and physical inventory while the mean discrepancy was $60.4 \%$. Discrepancy reported in Addis Ababa was high $(270 \%$ and $26 \%)$ respectively. ${ }^{15}$ In the present study, the discrepancy rate ranged from $0 \%$ to about $100 \%$ among health facilities, which was high as compared to research done in Gonder $(0 \%$ to $60 \%) .{ }^{16}$ The result showed that the rate of discrepancy was not uniform among health facilities. In one of the health centers, the physical count was less than bin card record balance for $27.3 \%$ TDs which was low as compared to research done in Gonder $(50 \%) .{ }^{16}$ This indicated that a certain amount of medicines was damaged or lost, or remain not updated when issued. The high discrepancies in the present study could be due to a lack of appropriate and continual filling of logistics forms like bin cards and a shortage of logistic records. Generally, discrepancies of more than $10 \%$ should cause concern and may require efforts to improve data quality. ${ }^{20}$

The study utilizes recorded TDs data from health facilities. Despite the study was conducted by data sources, the poor quality of information management systems in health institutions may introduce bias to the study. The availability of logistic data was limited the assessment of TDs availability to be six months. However, to capture all seasonal variation, it is more practical to retrieve 12 months data. Moreover, the cross-sectional nature of this study might make it harder to establish a temporal relationship.

\section{Conclusion}

The average availability of EMs in the public health facilities of Dessie town was $74.7 \%$. All public health facilities encountered stock out at least by one TDs. The health facilities were stock out for a significant percent of essential medicines on the day of visit and over the six months. The highest mean stock out day covered long duration is 3.5 months.

As the logistic information, most health facilities used logistic forms except stock card. Even though the bin card was used in six health facilities, bin card availability and up datedness for TDs at the survey period were not a hundred percent. There was a discrepancy in the stock between the bin card balance record and inventory stock at the survey period. However, the availability and proper utilization of logistics records were improved the availability of TDs.

To improve the availability of TDs; they should be managed by using different logistic forms like RRFs, 
IFRR, bin cards, and stock cards in each health facility. The health facilities manager, pharmacy head should emphasize TDs availability and for filling of logistic forms. So, to this, sufficient pharmacy professionals are needed. Therefore, recruitment is mandatory.

Computerized LMIS should be implemented in all health facilities. The PFSA should strengthen the availability of TDs for all public HFs in Dessie by the assurance of their supply. Zonal Health Department, Woreda Health Office, and PFSA should provide continual supervision of health facilities to monitor and fill the gap regarding the availability of TDs and the implementation of their LMIS by using a checklist.

\section{Abbreviations}

Ems, essential medicines; HCMIS, health commodity management information system; IFRR, Internal Facility Report and Resupply Form; LIAT, Logistics Indicator Assessment Tool; LMIS, logistics management information system; PSA, pharmaceutical supply agency; RRF, Report and Requisition Form; TDs, tracer drugs; WHO, World Health Organization.

\section{Data Sharing Statement}

The datasets are available from the corresponding author upon reasonable request.

\section{Ethical Consideration}

Before commencing data collection, ethical approval was obtained from Ethics Review Committee of the Department of Pharmacy, College of Medicine and Health Sciences, Wollo University (WU Phar/221/09). Then, the selected health facilities were informed with formal letters. The study was conducted in the selected facilities after getting permission from each facility administrator and Dessie town health office. During the consent process, they were provided with information regarding the purpose of the study, why and how they are selected to be involved in the study, and what will be expected of them. Since there is no anticipated risk, participants of the study have been asked for consent before participating in the study and verbal consent was obtained.

\section{Acknowledgments}

The authors would like to acknowledge Wollo University College of Medicine and Health Sciences Department of Pharmacy for providing us this opportunity to look at the retrospective study of the availability of TDs and implementation of their logistic management information system in public health facilities, Dessie, Ethiopia. Our very great gratitude also goes to store managers of all public health facilities and pharmacy heads who provided their precious time at the data collection time.

\section{Authors' Contribution}

All authors made a significant contribution to the work reported, whether that is in the conception, study design, execution, acquisition of data, analysis and interpretation, or in all these areas; took part in drafting, revising or critically reviewing the article; gave final approval of the version to be published; have agreed on the journal to which the article has been submitted; and agree to be accountable for all aspects of the work.

\section{Funding}

There is no funding to report.

\section{Disclosure}

The authors declare that they have no potential competing interest.

\section{References}

1. World Health Organization. WHO model list of essential medicines: 17th list. March 2011

2. World Health Organization. Equitable access to essential medicines: a framework for collective action. World Health Organization; 2004.

3. PFSA. Standard operating procedures manual for the integrated pharmaceuticals logistics system in health facilities of Ethiopia. Second Edition. Addis Abeba: Ethiopia; 2015. Available from: www.pfsa.gov.et/webadmin/ . . /IPLS\%20-\%20SOP\%20-\%20Nov\% 20-\%202015.pdf.

4. USAID Deliver. The Logistics Handbook: A Practical Guide for Supply Chain Managers in Family Planning and Health Programs. Project Task Order 1. Arlington, VA: USAID; 2007.

5. USAID/SIAPS. The SIAPS Approach to Strengthening Pharmaceutical System. Arlington, VA: Management Sciences for Health; 2014.

6. Blanas DA, Ndiaye Y, Nichols K, Jensen A, Siddiqui A, Hennig N. Barriers to community case management of malaria in Saraya, Senegal: training, and supply-chains. Malar J. 2013;12(1):95. doi:10.1186/1475-2875-12-95

7. Mendis S, Fukino K, Cameron A, et al. The availability and affordability of selected essential medicines for chronic diseases in six low-and middle-income countries. Bull World Health Organ. 2007;85:279-288. doi:10.2471/BLT.06.033647

8. Chetley A, Hardon A, Hodgkin C. How to Improve the Use of Medicines by Consumers. 2007:viii-245.

9. World Health Organization. Management of drugs at health centre level: training. 2004.

10. World Health Organization. Service availability and readiness assessment (SARA): a methodology for measuring health systems strengthening. Geneva; Accessed November 7, 2012:2013. 
11. Jitta J, Whyte SR, Nshakira N. The availability of drugs: what does it mean in Ugandan primary care. Health Policy. 2003;65(2):167-179. doi:10.1016/S0168-8510(03)00003-4

12. Defd. Defining and measuring accessing to essential medicines, vaccines, health commodities; report for who-msh constitute meeting: Fernery Voltaire. France; December 11-13, 2004.

13. Cameron A, Ewen M, Auton M, Abegunde D. The world medicines situation 2011: medicines prices, availability and affordability. 2011.

14. Islam M. Health systems assessment approach: a how-to manual. 2007.

15. Mudzteba M. Assessment of pharmaceutical logistics system in health centers of Addis Ababa. Ethiopia: Addis Ababa University; 2014.

16. Fentie M, Fenta A, Moges F, et al. Availability of essential medicines and inventory management practice in primary public health facilities of Gondar town, north West Ethiopia. J PharmaSciTech. 2015;4 (2):54-56.

17. Bruno O, Nyanchoka OA, Ondieki MC, Nyabayo MJ. Availability of essential medicines and supplies during the dual pull-push system of drugs acquisition in Kaliro District Uganda. J Pharma Care Health Sys S2-006. 2015;10:2.

18. Central Statistical Agency. Population and Housing Census 2007 Report. Available from: http://catalog.ihsn.org/index.php/catalog/ 3583/download/50086. Accessed July 13, 2017.

19. Federal Ministry of Health of Ethiopia. Health Management Information system. Addis Abeba: Ethiopia.

20. Snow J. Inc./DELIVER. Logistics indicators assessment tool (LIAT). 200.
21. Wagenaar BH, Gimbel S, Hoek R, et al. Stock outs of essential health products in Mozambique-longitudinal analyses from 2011 to 2013. Trop Med Int Health. 2014;19(7):791-801. doi:10.1111/ tmi. 12314

22. Arhinful DK. WHO pharmaceutical situation assessment: level ii-health facilities survey in Ghana. Ghana: Ministry of Health; 2009.

23. Nyanwura EM. Essential medicines availability and affordability: a case study of the top ten registered diseases in Builsa District [Doctoral dissertation]. University of Ghana.

24. Harrington J. Access to essential medicines in Kenya: intellectual property, anti-counterfeiting and the right to health. 2014.

25. Abiye Z, Tesfaye A, Hawaze S. Barriers to access: availability and affordability of essential drugs in a retail outlet of a public health center in south western Ethiopia. J Appl Pharm Sci. 2013;3(10):11.

26. Ministry of Health and Social Welfare. In depth assessment of the medicines supply system in Tanzania. Tanzania; 2008.

27. World Health Organization. How to investigate drug use in health facilities: selected drug use indicators. Geneva: World Health Organization; 1993.

28. Carasso BS, Lagarde M, Tesfaye A, Palmer N. Availability of essential medicines in Ethiopia: an efficiency-equity-trade off? Trop Med Int Health. 2009;14(11):1394-1400. doi:10.1111/j.1365-3156.2009. 02383.x

29. Awaya T, Ohtaki KI, Yamada T, et al. Automation in drug inventory management saves personnel time and budget. Yakugaku Zasshi. 2005;125(5):427-432. doi:10.1248/yakushi.125.427
Integrated Pharmacy Research and Practice

\section{Publish your work in this journal}

Integrated Pharmacy Research and Practice is an international, peerreviewed, open access, online journal, publishing original research, reports, reviews and commentaries on all areas of academic and professional pharmacy practice. This journal aims to represent the academic output of pharmacists and pharmacy practice with particular focus on integrated care. All papers are carefully peer reviewed

\section{Dovepress}

to ensure the highest standards as well as ensuring that we are informing and stimulating pharmaceutical professionals. The manuscript management system is completely online and includes a very quick and fair peer-review system, which is all easy to use. Visit http://www.dovepress.com/testimonials.php to read real quotes from published authors. 